\title{
ESTUDO SOBRE PERDAS NO PROCESSAMENTO INDUSTRIAL DO TOMATE*
}

Alaise R. Gil $* *$

Homero Fonseca***

Humberto de Campos:*;:

Maria I.R. Sanchez*****

\section{RESUMO}

\begin{abstract}
Neste trabalho foram pro postas fórmulas para se calcular - rendimento esperado, em polpa concentrada, em indústrias de processamento de tomate, compa rando-o com o rendimento realmeñ te obtido, e visando controlar o desempenho da indústria.
\end{abstract}

* Entregue para publicação em 18/03/87.

$*$ B B ióloga

*** Departamento de Tecnologia Rural, E.S.A. "Luiz de Queiroz" - Piracicaba, SP

*:* Departamento de Matemática e Estatistica, E.S.A. "Luiz de Queiroz" - Piracicaba, SP $* * * * *$ Economista Doméstica 
Para testar estas förmulas foi feito um estudo comparativo entre o rendimento esperado cal culado e o rendimento real, tō mando por base os assentamentos de uma indūstria, de porte médio, de processamento de tomates, do Estado de São Paulo, nos anos agrícolas de 1981 e 1982. Conco mitantemente foi feita uma anál se das perdas, na forma de des cartes, na esteira de seleção de sementes e pele, nas despolpa deiras e tambēm uma verificaçāo do Brix médio ponderado, nas duas safras.

Os resultados mostraram que as förmulas säo adequadas para o cálculo do rendimento esperado pois as diferenças, com o rendi mento real, obtido foram de $-1,49 \%$ e $+1,74 \%$ em 1982. As per das de tomate (descartes) foram consideradas elevadas em compara ção com as de outros países que significa tomate de baixa qua lidade. 0 Brix médio ponderado mensal que alcançou até 5,62 foi significativamente maior que o de anos anteriores.

\section{NTRODUÇÃO}

o tomate $\bar{e}$, provavelmente, a hortaliça mais importante, não só em termos de produção 
como também em valor econômico, pois é a mais industrializada.

A industria do tomate no Brasil teve iní cio, durante a Segunda Guerra Mundial e a pa $\bar{r}$ tir de 1950 tomou grande impulso. Hoje situa- se entre os grandes produtores mundiais junta mente com os Estados Unidos, Itälia, Grécia, Egito, Portugal e outros (MINAMI $\varepsilon$ FONSECA, 1982), sendo São Paulo o Estado maior produtor no Brasil.

Numerosas indústrias processadoras de to mate de grande, médio e pequeno portes operām no Estado de Säo Paulo. A matëria-prima é ad quirida do produtor através de contrato de for necimento e a sua qualidade é variável confor me o produtor, época do ano, regime de chuvas e cuidados na colheita, no transporte e no des carregamento.

o rendimento industrial depende, além dos fatores já citados, do critērio de seleção, tipo de equipamento utilizado, e outros fato res imponderáveis. As industrias, para fins de custos, devem manter o melhor controle possí vel de toda a matéria-prima entrada e de todō produto acabado, sem o que não há possibilida de de se ter uma quantificação de perdas e me $\bar{s}$ mo de eventuais desperdícios ou desvios de prō dutos.

De acordo com LEONI e BELLUCCI (1980), o calculado teórico para se avaliar o rendimento industri al do tomate é atravēs do rendimento em polpa coñ centrada que é expresso em x quilogramas de con centrado com um determinado Brix (R), obtido apartir de $100 \mathrm{~kg}$ de tomate cujo suco tem tam bēm um determinado Brix (r) levando-se em coñ 
sideração o peso de resíduo (cascas e semen tes) resultantes. A tórmula proposta para o căl culo, por estes autores, é :

$$
X=r / R(100-C)
$$

Todavia, esta förmula nāo leva em consi deração o tomate retirado na esteira de sele ção, que no Brasil é não desprezível, nem o sü co recuperado do resíduo.

Por este motivo, essa förmula correspon

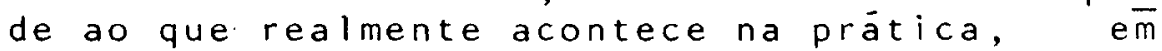
nosso pais.

Neste trabalho estamos propondo algumas förmulas de cálculo, levando em consideração aqueles fatores, que possam levar a uma aproxi mação maior com a realidade. Para testar estas förmulas fizemos um estudo comparativo entre o Rendimento Esperado, Calculado e o Rendimento Real, registrado, tomando por base os assenta mentos e registros de uma indūstria de portē mëdio do Estado de São Paulo. Aproveitando es ses registros fizemos tambëm uma avaliação das perdas mensais nas duas safras e uma análise do Brix médio mensal ponderado.

MATERIAL E METODOS

O material utilizado para este estudo são os registros diārios de uma indústria de porte médio de processamento de tomate do Esta do de São Paulo, nos anos agrícolas de $198 \overline{1}$ (registros de maio de 81 a janeiro de 82 ) e de 1982 (março a dezembro). 
Os dados registrados correspondem à :

a) soma total de peso de tomate entrado no dia - PT;

b) percentagem média ponderada de söli dos solúveis, expressa em graus Brix, do sucō fresco do tomate no dia - BT

c) peso de descarte na esteira de sele ção, no dia - RES;

d) peso do resíduo das despolpadeiras, no dia - RD;

e) peso, de polpa concentrada a $26^{\circ} \mathrm{Brix}$, obtido no dia - $P P_{R}$;

f) peso do suco recuperado do resíduo das despolpadeiras no dia - PSR;

g) Brix médio do suco recuperado do resí duo das despolpadeiras - BSR . .

Embora esta indústria não tenha efetuado - esgotamento do residuo das despolpadeiras pa ra recuperação de suco, os dados $f$ e g devem entrar no cälculo para maior aproximação da rea lidade, quando esta operação for efetuada.

o cälculo do rendimento será efetuado através das förmulas propostas:

(1) Rendimento teórico

$$
\frac{\sum P T \times B T M}{26}=\text { peso de polpa concentra }
$$

da a $26^{\circ} \mathrm{Brix}$ se não houvesse erro nem perdas. Se a indústria concentra a polpa a um Brix di 
ferente, este valor, e não 026 , deve ser ut lizado nas förmulas.

(2) Perdas

$$
\frac{(R E S+R D) \times B T_{M}}{26}=\text { peso de polpa a }
$$

$26^{\circ}$ Brix (teōrico) perdida nos descartes e no resíduo.

(3) Recuperados

$$
\frac{P S R \times B S R M}{26}=\text { peso de polpa a } 26^{\circ} \mathrm{Brix}
$$

recuperada dos resíduos.

Rendimento esperado RE: (1) - (2) + (3)

As perdas reais, ou presuntivamente re ais, não registradas podem ser avaliadas pela diferença entre o rendimento esperado e o ren dimento real $P P_{R}$.

A fim de se proceder ao estudo estatísti co das perdas foram considerados os dados meñ sais do processamento. 0 perílodo abrangido fo $\bar{i}$ - de maio de 1981 a dezembro de 1982 exceptuan do-se o més de fevereiro de 1982. Para cada mês foram realizadas as seguintes anälises e determinações:

a) correlação entre o rendimento real e - rendimento esperado;

b) estudo de regressão linear do rendi mento real (y) em funcão do rendimento esperā do $(x)$;

c) estimativa das percentagens de perda 
na esteira, na despolpadeira e total, segun do a förmula:

Porcentagem de perda $=\frac{\text { perda }(\mathrm{kg})}{\text { perdado tomate }} \times$ $\times 100$

d) estimativa das perdas mëdias diàrias: na esteira, na despolpadeira e total e seus respectivos intervalos de confiança e coefi ciente de variação.

\section{RESULTADOS E DISCUSSAO}

os registros mensais do tomate recebido, Brix médio ponderado, perdas na esteira de se leção, nas despolpadeiras, rendimento esperá do e real são os constantes das Tabelas 1 à 4. Os resultados das análises estatísticas são os das Tabelas 5 e 6 .

Como se pode observar pela Tabela 5 na primeira safra (1981) a correlação entre o ren dimento esperado e o real variou de $r=0,607 \overline{8}$ até 0,9942. Esta variação, cremos, deve ser creditada, principalmente, a falhas no aciompa nhamento ou rastreamento do produto obtido em função da matéria-prima recebida. Esta situa ção foi corrigida nos primeiros meses da sá fra seguinte (1982) quando, a partir de maio, aquela correlação variou de $r=0,8981$ a 1,00 . Esta variaçāo, todavia, não influiu no compu to anual. Esta afirmaça pode ser demonstrada se tomarmos os valores totais dos anos 81 e 82 e calcularmos a percentagem de diferença entre o rendimento esperado, calculado pelo procedimento por nós proposto, e o rendimento 
real:

$1981:$

polpa concentrada a $26^{\circ} \mathrm{Brix}$

Rendimento esperado: $1.621 .904 \mathrm{~kg}$

Rendimento real : $1.646 .514 \mathrm{~kg}$

$\Delta=24.610 \mathrm{~kg}$

$\%$ diferenca $=-1,49 \%$ (sobre o real)

1982 :

polpa concentrada a $26^{\circ} \mathrm{Brix}$

Rendimento esperado: $3.418 .313 \mathrm{~kg}$

Rendimento real $: 3.359 .766 \mathrm{~kg}$

$\Delta=58.547 \mathrm{~kg}$

$\%$ diferença $=+1,74 \%$ (sobre o real)

As diferenças de $-1,49 \%$ a $+1,74 \%$ são mí nimas e, cremos, deve ser produto do cálculo do Brix médio ponderado, que é o parámetro de císivo nos cálculos pois é o único que não pō de ser medido no todo e sim por amostragem, iñ cluindo consequentemente uma pequena margem de erro.

Dadas as diferenças extremamente peque nas que foram observadas, o processo de cálcu lo do rendimento esperado ora proposto é bas tante significativo e pode ser utilizado para aferir a eficiéncia da indústria, bem como ofe recer dados importantes para se identificar on de se situam as perdas do processo e então prō curar minimizä-las.

Examinando as Tabelas 3 e 4 podem verifi car que as perdas mensais na esteira variaram de 2,38 a $7,12 \%$ na safra de 1981 e de 1,93 a $4,39 \%$ na safra de 1982 o que, conquanto um pou co altas, são razoáveis para as candiçóes dé São Paulo. Todavia, em países da Europa e nos 


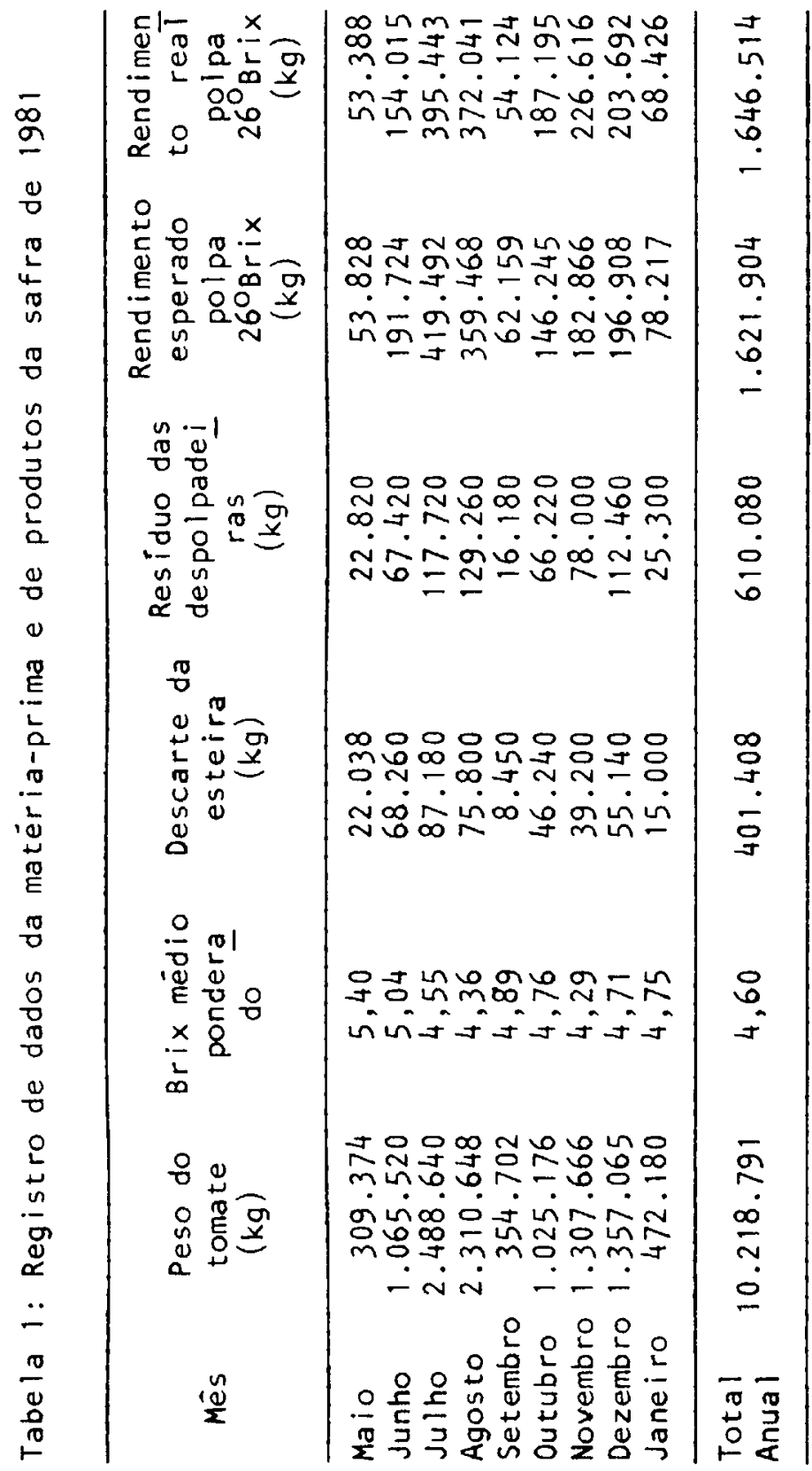




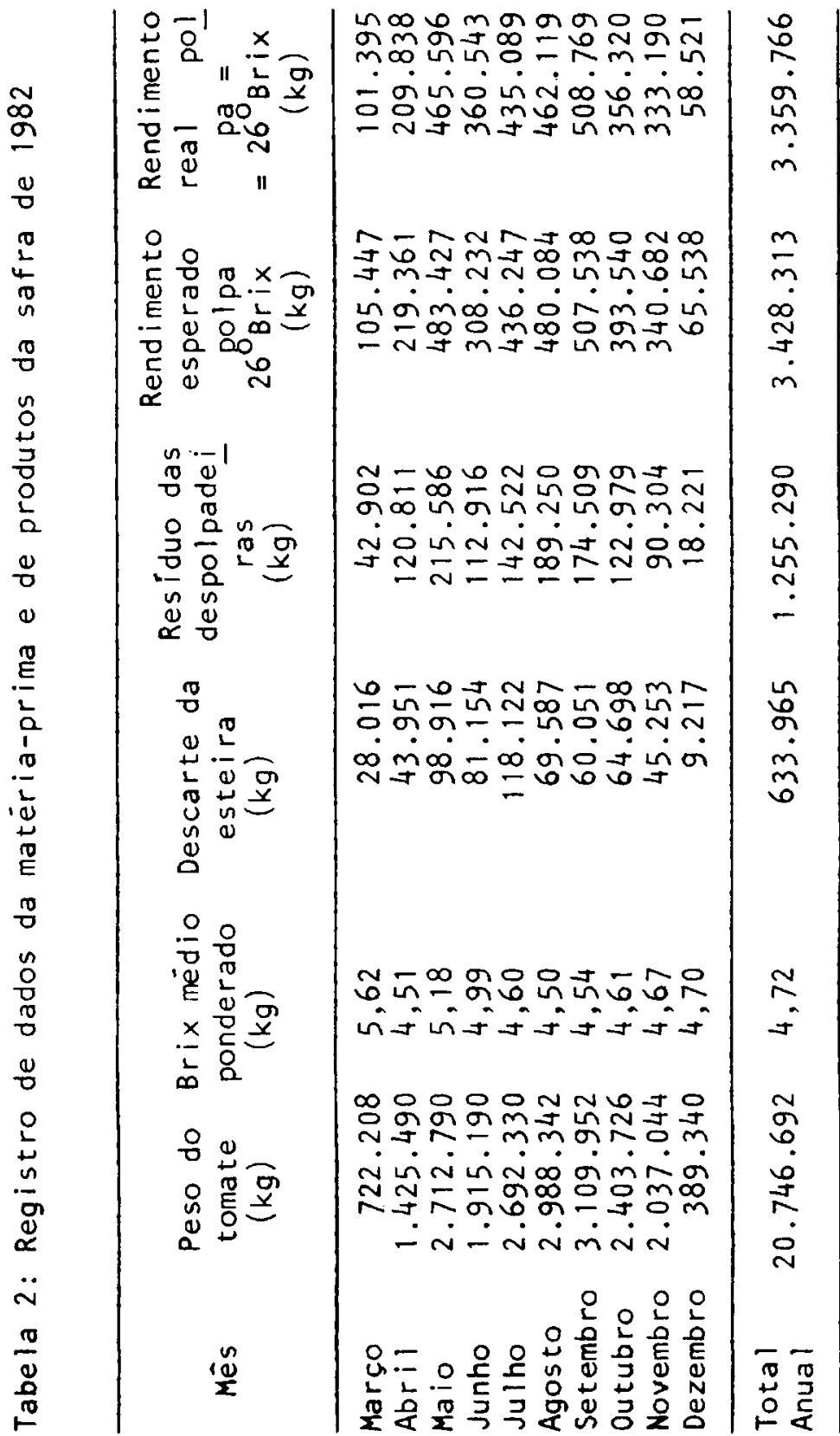




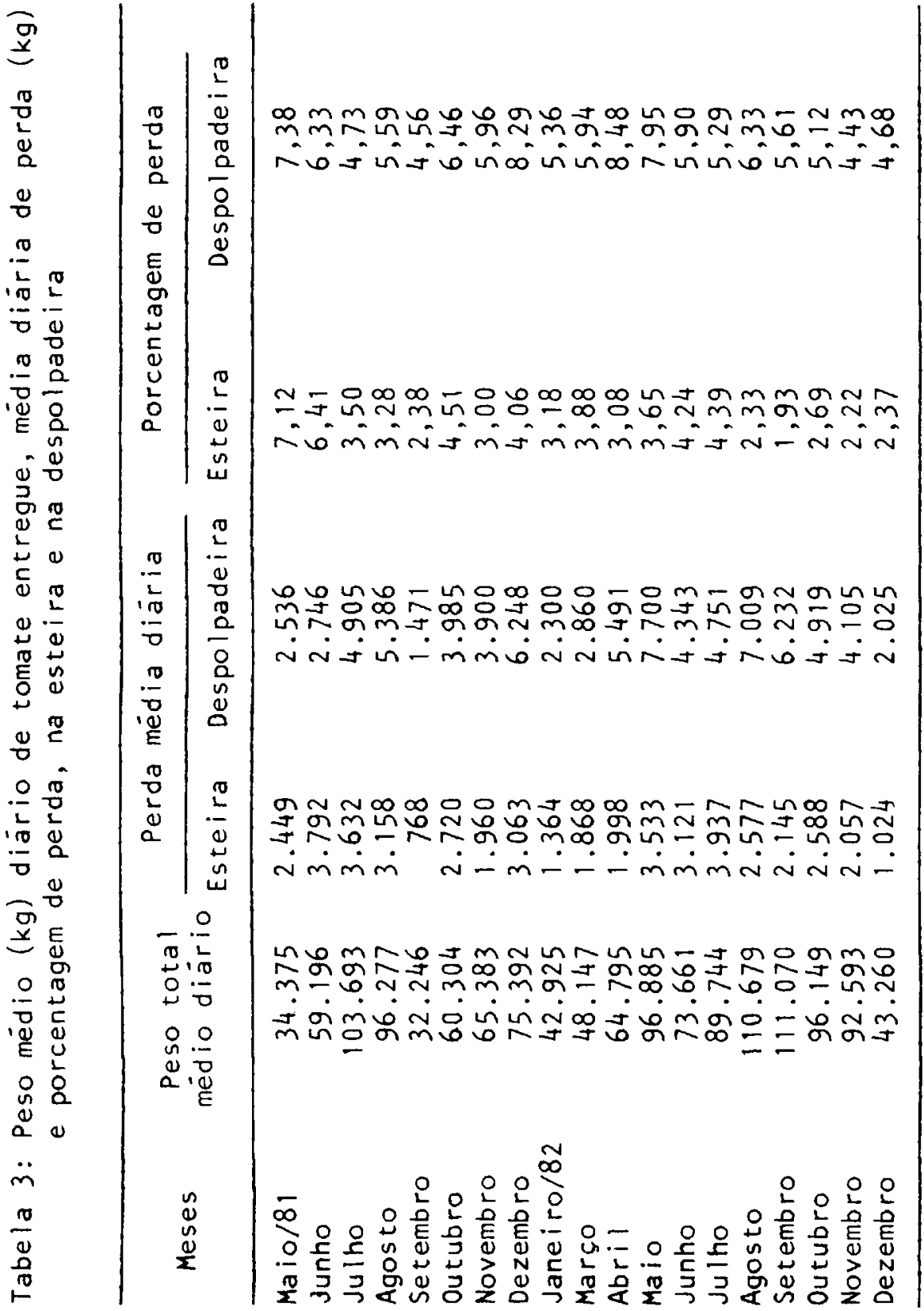




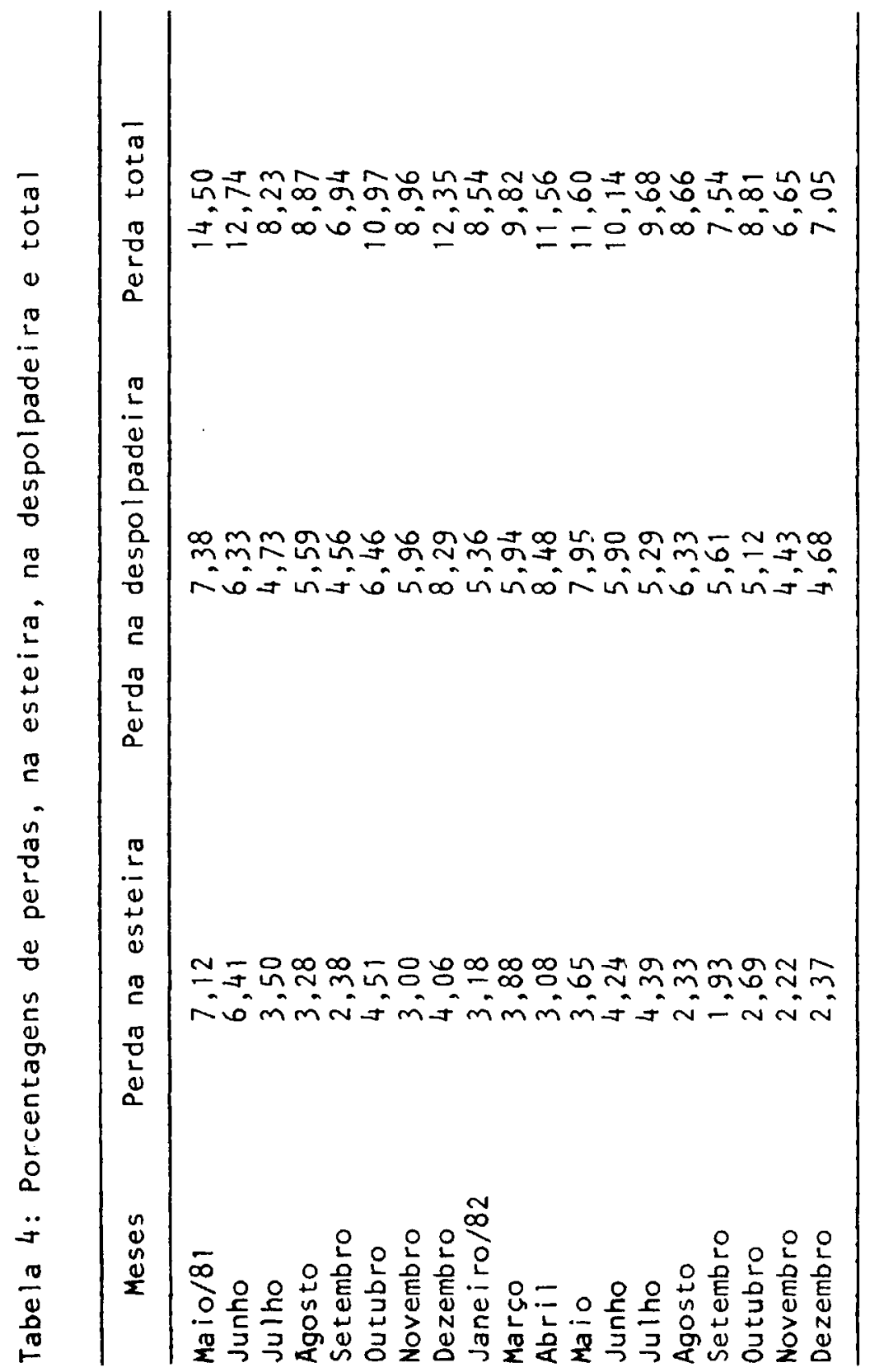




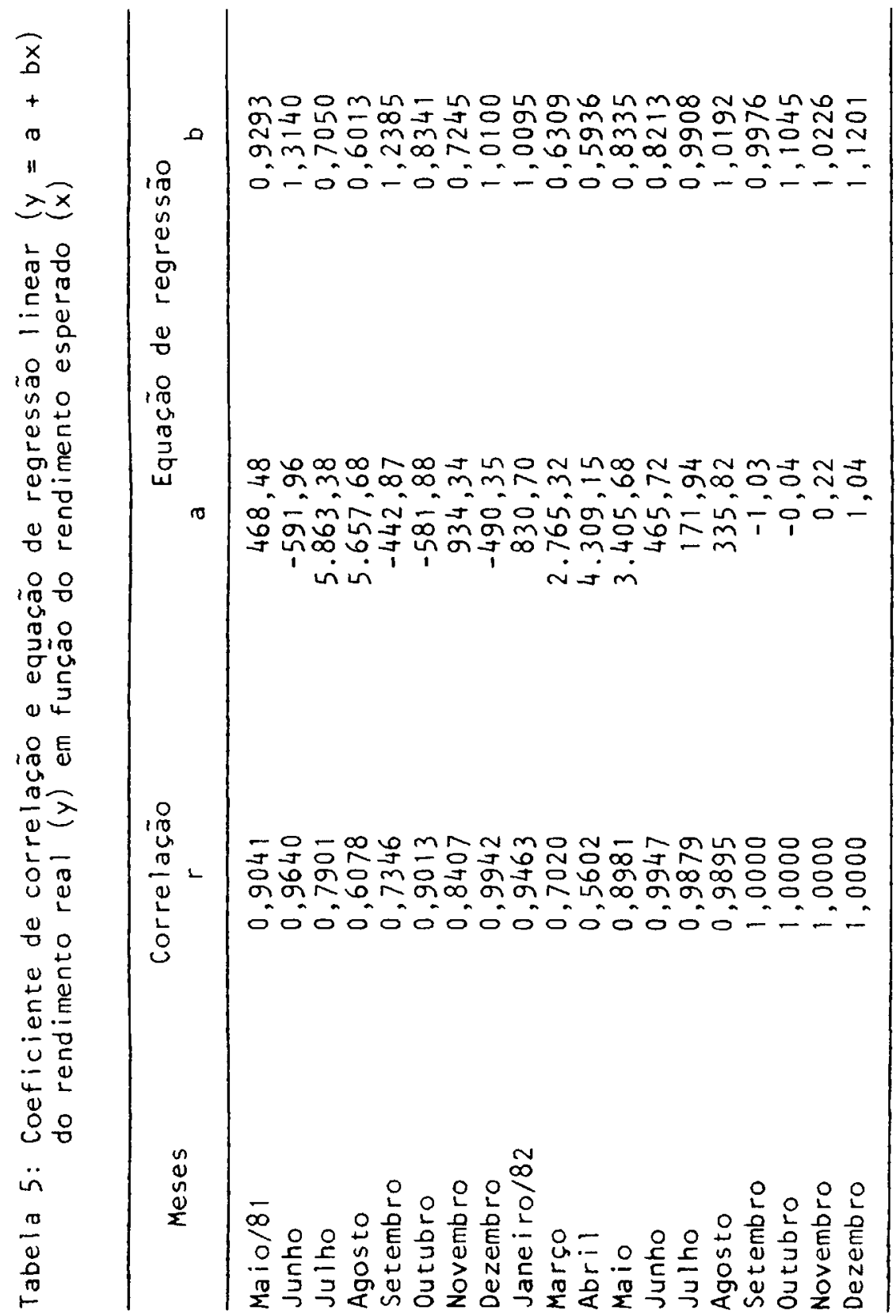




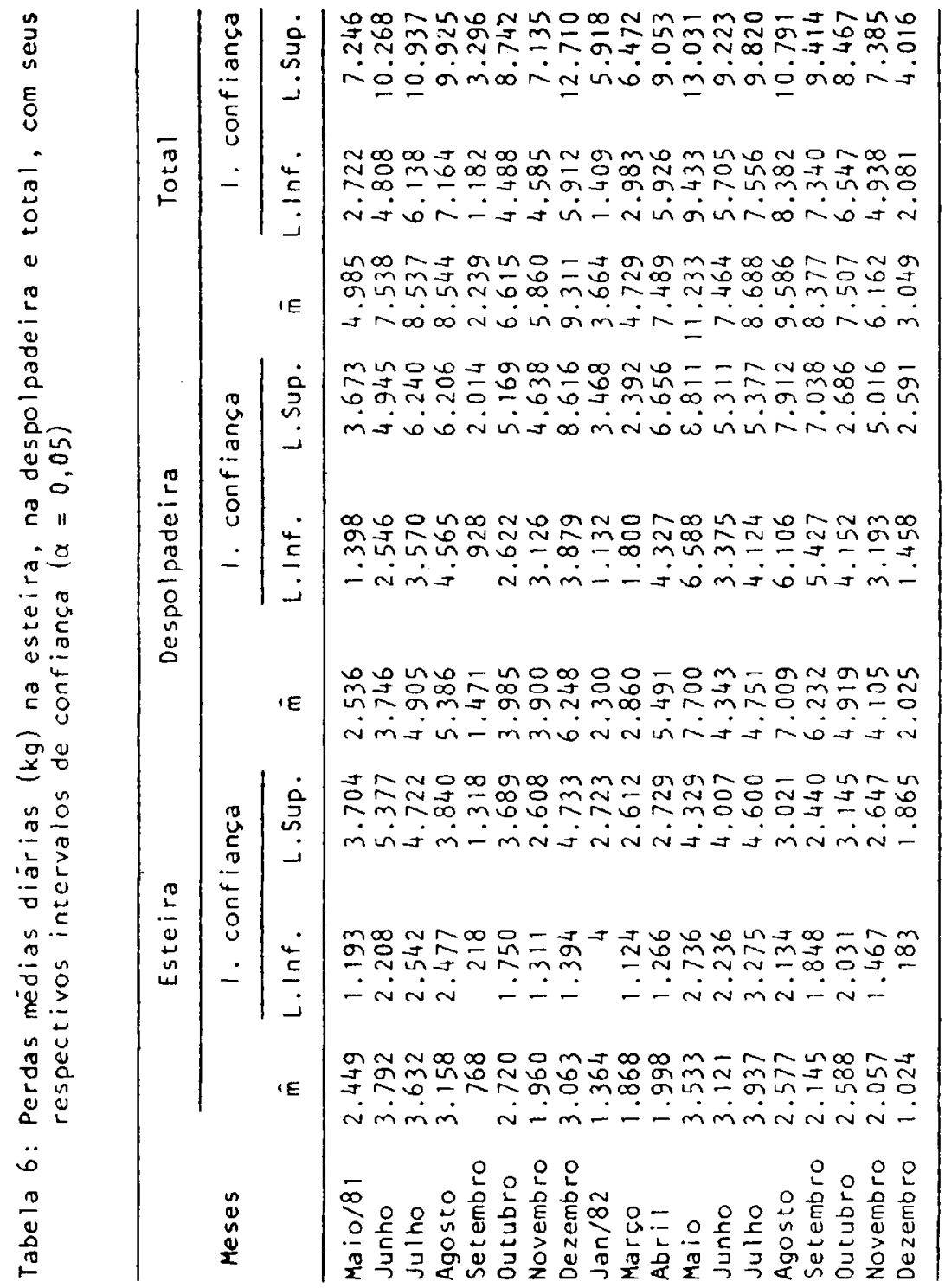


EUA, essas perdas são bem menores. As perdas relativamente elevadas aqui verificadas espe Iham a má qualidade da matéria-prima entregue na indústria considerando-se ainda que estas não fazem uma seleção rigorosa na esteira. To mando-se por base as perdas totais na este $\bar{i}$ ra, verifica-se que, em 1981 , cerca de 71 toㅡ neladas de polpa a $26^{\circ} \mathrm{Brix}$ deixaram de ser pro duzidas, e em 1982, 115 toneladas, perdas con sideräveis.

As perdas, na forma de cascas e semen tes na despolpadeira variaram de 4,56 a $8,29 \%$ em 1981 e de 4,43 a $8,48 \%$ em 1982, e podem ser consideradas normais.

As perdas totais, englobando as duas sa fras variaram de 6,65 a $14,50 \%$.

- Brix médio ponderado em 1981 variou de 4,29 a 5,40 e em 1982 de 4,50 a 5,62 o que representa um avanço sobre alguns anos antes quando, aqueles valores, variavam em torno de 4,00. A introduça de novas variedades teve marcada influéncia no aumento do Brix, que é fundamental paramelhorar o rendimento indus trial e a rentabilidade da empresa.

\section{CONCLUSOES}

Os resultados obtidos permitem tirar as seguintes conclusões relevantes:

1. A förmula de cälculo do rendimento esperado proposta permitiu uma aproximaço muito significativa com o rendimento real ob tido, com margens de erro de $-1,49 \%$ na safra 
de 1981 e de $+1,74 \%$ na safra de 1982 .

2. As perdas totais na esteira (descar tes) foram consideradas relativamente altas em comparação com as de outros países. Essas perdas equivaleram a 71 toneladas, em 1981 e 115 toneladas, em 1982 , de polpa a $26^{\circ} \mathrm{Brix}$.

3. As perdas elevadas registradas espe Iham a má qualidade da matēria-prima entregué na indūstria.

4. 0 Brix médio ponderado mensal variou de 4,29 a 5,40 em 1981 e 4,50 a 5,62 em 1982 - que representa um avanco sobre anos anterio res.

SUMMARY

STUDY ON LOSSES IN THE TOMATO
PROCESSING INDUSTRY

In the present work formulas were propo sed to calculate the expected yield of concen trated tomato pulp as an aid to control the processing industry performance.

In order to test these formulas a compa rative study between the calculated expected yield and the obtained yield utilizing daily registers of a medium size processing indus try of the State of São Paulo, Brazil, of 1981 and 1982 crop was made.

In the same study the losses of toes discarded in the selection belt and as 
seeds and peel from the pulpers. The Brix mean values were also evaluated.

The results showed that the formulas are fitted to the purpose they were developed since the difference between expected and ob tained yields were $-1,49 \%$ in 1981 and $+1,74 \%$ in 1982 .

The losses in discarded tomatoes were considered high when compared to those of other countries which means low quality raw material.

The relatively high Brix mean values, up yo 5.62, were considered a very good ad vance over previous years.

\section{LITERATURA CITADA}

LEONI, C.; BELLUCCI, G., 1980. Le Conservedi Pomodoro. Stazione Sperimentale per I'In dustria delle Conserve Alimentari. Parma, Itália. $175 \mathrm{pp}$.

MINAMI, K.; FONSECA, H., 1982. Tomate. Produ ção, Pré-Processamento e Transformação Agro industrial. Sērie Extensão Agroindustrial no 8. Secretaria da Indüstria, Comércio, Ciência e Tecnologia do Estado de São Pau lo. $92 \mathrm{pp}$. 